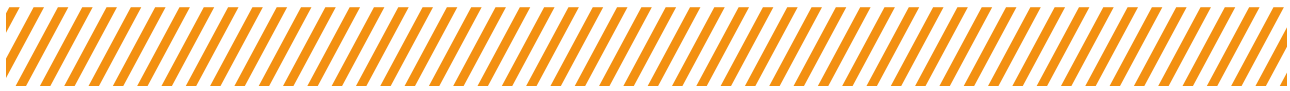

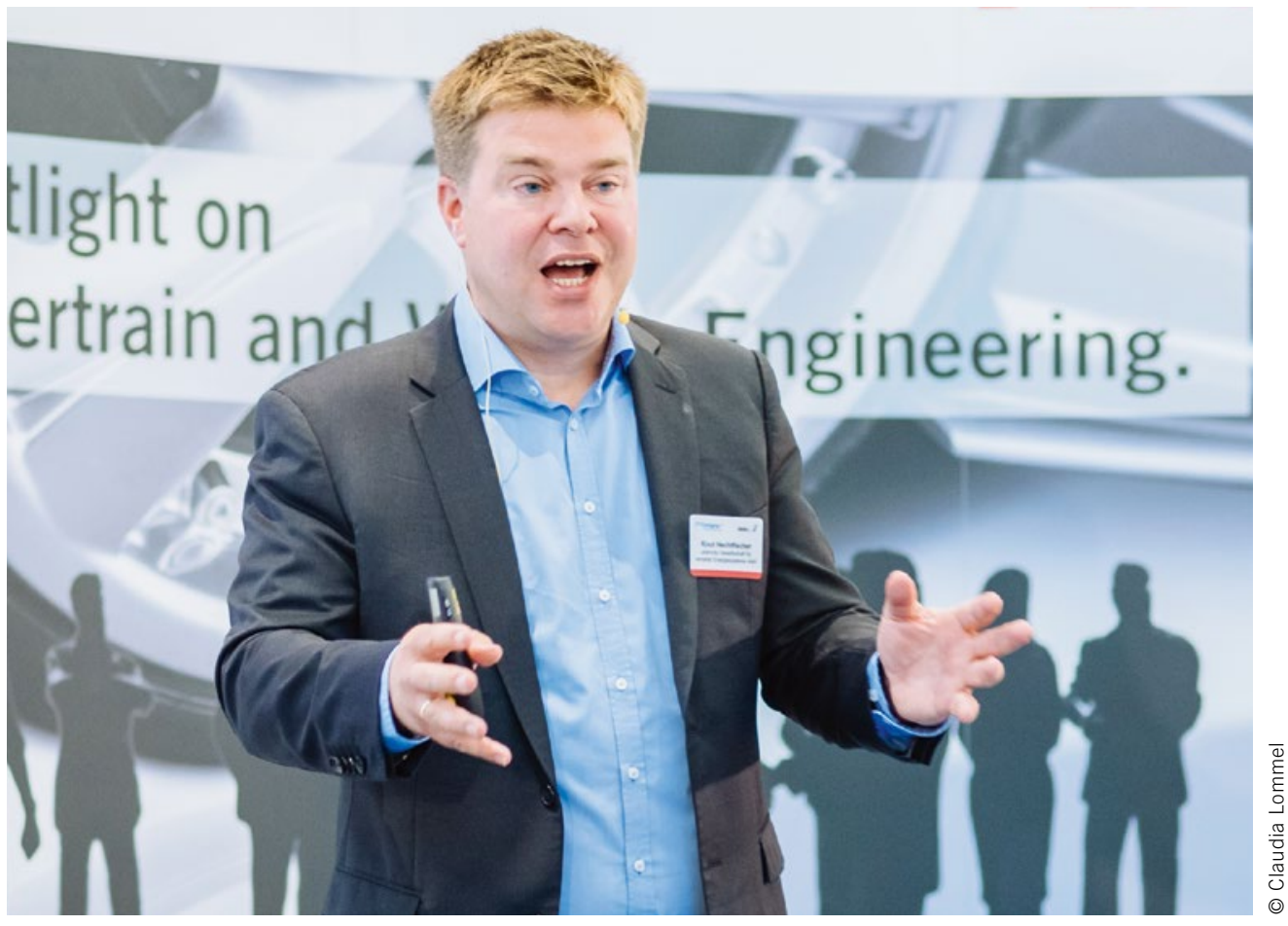

Knut Hechtfischer

Founder of ubitricity, Gesellschaft für verteilte Energiesysteme, Berlin (Germany)

\section{Charging Is Not the Same as Refueling}

Ask a representative of a German carmaker why the company has neglected to make any significant investments in its own charging infrastructure for electric vehicles and you're likely to be met by a look of astonishment. If you persist, expect to be reminded of the fact that carmakers don't operate their own gas stations, either, and that work is already being done by others in other sectors to establish a fast-charge infrastructure. The question, it seems, is irrelevant. But is it really that simple?

Charging is, after all, not the same as refueling. It is an altogether more complex matter when vehicle owners can typically avail themselves of slow-charging options at home and at work, and when the electricity itself is supplied by a power company of their choice - or comes from their own rooftops. Moreover, one can expect that the type of charging involved, the time of day, the controllability and other factors will all have an impact on the associated cost. And finally, there is nothing to prevent automobile manufacturers from becoming producers of electricity or from supplying electricity to homes, places of work and public-access charging stations. Indeed, it would be comparatively easy today to integrate energy-supply services into the traditional automotive value-added chain, something that was never the case in connection with the oil industry.

OEMs have begun to consider issues such as invoicing modalities for e-car charging, securing the economic viability of charging infrastructure and optimizing customer comfort.
The prospects here have proven to have considerable motivational content, and the scope of opportunities could actually be expanded. It seems clear that taking a more assertive approach to positioning oneself as a developer, proprietor or operator of charging infrastructure would inspire a certain agility and the capacity to meet more demanding requirements. This would be an excellent opportunity to market the vehicles of a manufacturer as superior and, of course, more cost-effective in terms of their overall power-related characteristics. Regrettably, the value of new business segments here has been underestimated. And it looks like no traditional manufacturers are interested in playing a larger role on the energy side of electric vehicles. Instead, only a few companies even recognize charging infrastructure and power services as relevant to their competitiveness, emerging factors that one can, and indeed, must shape. Will this change? Will charging and invoicing standards be good enough for the manufacturers of premium brands? And what will happen, for instance, if some manufacturers succeed in supplying electricity to their customers at significantly lower prices while others are caught without the means of doing so?

As a country that is clearly interested in new, sustainable systems of energy supply, Germany would seem to be predestined to play a leading role when it comes to embedding electric vehicles in the energy sector. But time is running out. And once platforms have been established, it will be too late. 